\title{
Right Ventricular Function Assessment in Sickle Cell Anaemia Patients Using Echocardiography
}

\author{
Opeyemi 00NI1, Adebiyi AA ${ }^{2 *}$, Akinyemi AJE² and Akingbola TS ${ }^{3}$ \\ ${ }^{1}$ Department of Medicine, Bowen University Teaching Hospital, Nigeria \\ ${ }^{2}$ Department of Medicine, University College Hospital, Nigeria \\ ${ }^{3}$ Department of Haematology, University College Hospital, Nigeria
}

*Corresponding author: Adewole A Adebiyi, Department of Medicine, University

\section{Research Article \\ Volume 3 Issue 1}

Received Date: February 13, 2019

Published Date: March 15, 2019

DOI: $10.23880 /$ hij-16000136

College Hospital, Ibadan, Oyo state, Nigeria, Tel: +234(0)8060450458; Email: wadebiyi@gmail.com

\section{Abstract}

Right ventricular dysfunction has been linked to poor prognosis in people with sickle cell anaemia (SCA). There is however a paucity of studies on right ventricular function in SCA. The objectives were to determine right ventricular function in subjects with SCA using echocardiography and compare results with controls. The study design was descriptive and cross sectional. Echocardiography was done to assess both systolic and diastolic function of subjects with SCA and controls. Eighty-six subjects with SCA and eighty-nine controls with haemoglobin A were recruited. The sickle cell group had a mean age of $27.6 \pm 7.6$ while controls were 28.9 \pm 8.9 . Right ventricular fractional area change (RVFAC) was not significantly different between both groups. However, tricuspid annular plane systolic excursion (TAPSE) and peak tricuspid annular systolic velocity (S) were increased in the sickle cell group as compared with controls. The sickle cell group also had more diastolic dysfunction (Transtricuspid early (E)/late (A) diastolic filling ratio) than controls, though not attaining statistical significance. The Transtricuspid E/E' was significantly increased in subjects as compared to controls. Binary logistic regression revealed low body mass index (BMI) as the predictor of diastolic dysfunction among the sickle cell subjects and controls studied. Systolic function is largely preserved in sickle cell subjects. TAPSE and S' values are actually increased in the subjects as compared to controls, suggesting that the right ventricle becomes hyperdynamic to compensate for the chronic anaemia. Diastolic dysfunction is present in sickle cell subjects with the important predictor being underweight BMI.

Keywords: Sickle Cell Anaemia; Echocardiography; Haematology; Hyperdynamic; Trabeculations; Malabsorption

Abbreviations: SCA: Sickle Cell Anaemia; RVFAC: Right Ventricular Fractional Area Change; RVD: Right Ventricular Dysfunction; BP: Blood Pressure; PCV: Packed Cell Volume; BMI: Body Mass Index; PWD: Pulsed-Wave
Doppler; CWD: Continuous Wave Doppler; TDI: Tissue Doppler Imaging; IVRT: Isovolumic Relaxation Time; TAPSE: Tricuspid Annular Plane Systolic Excursion; TRJ: 
Tricuspid Regurgitant Jet Velocity; DCT: Deceleration Time.

\section{Introduction}

Right ventricular dysfunction (RVD) is a known complication of SCA, usually as a sequel of pulmonary hypertension (PHT) [1]. While the timeline of onset of clinically significant PHT has been noted from the 5th decade of life, increased right ventricular mass index has been noted in $16 \%$ of children as early as 2 nd decade of life [2] RVD has been found in individuals with SCA, even in the absence of overt PHT [3] and once it sets in, RVD contributes to morbidity and mortality in this group of patients. Pulmonary hypertension, in a way akin to systemic hypertension, has been proposed to cause structural changes in the right ventricle, with functional abnormalities occurring in the late stages [4]. Sickle cell anaemia has been shown to cause left ventricular dysfunction and PHT [5]. Both entities are known risk factors for right ventricular dysfunction [6]. However, there is a relative paucity of studies on the adult right ventricle in this group of people. The general objective of this study was therefore to evaluate right ventricular function in subjects with SCA with using echocardiography and compare results with controls.

\section{Methods}

The study was carried out at both the Cardiology and Haematology units of the University College Hospital, Ibadan. The study was descriptive, cross sectional in design.

\section{Subjects}

The subjects were adult outpatients of the Haematology clinic. The subjects were confirmed as homozygous for haemoglobin $S$ with the aid of haemoglobin electrophoresis. None of the subjects was on any chronic transfusion protocol and they were all indigenous Africans. The subjects were in steady state. For the purpose of this study, steady state was defined as a point in time when the patient is free from SCA-related crisis for one month prior to evaluation. There was no history of blood transfusion one month prior to evaluation; no hospital admissions within 3 days of evaluation; no treatment with medications that affect the blood count within three weeks prior to evaluation and no history of intercurrent illness (such as infection) within the previous four weeks [7]. Exclusion criteria for subjects include those in atrial fibrillation, those known with severe lung disease, HIV infection, rheumatic heart disease, connective tissue disorders, concomitant hypertension, diabetes mellitus and those with poor echocardiographic window.

\section{Controls}

They were apparently healthy adults with haemoglobin A (HBA) recruited from the medical and non- medical staff of the hospital community. They had no clinical history of cardiovascular problems and had no evidence of structural heart disease. They were comparable in age and sex with subjects with SCA. Exclusion criteria for controls were those with known cardiac disease, those with hypertension, those known with diabetes mellitus, those that smoke cigarettes and those with significant alcohol use.

\section{Sampling Methodology and Sample Size Calculation}

A convenient sampling method was used for the study. Eligible subjects were consecutively recruited from the haematology clinic. Using the parameters of peak tricuspid annular systolic velocity $\left(S^{\prime}\right)$ from a previous study [8], and a study designed to detect a minimum difference in $\mathrm{S}^{\prime}$ of $1.2 \mathrm{~cm} / \mathrm{s}$ between the subjects and controls and a power of $90 \%$ with a $5 \%$ level of significance, the minimum sample size required for the study was 75 subjects per group. The subjects were consecutively recruited into the study, after a written informed consent was obtained.

\section{Ethical Approval}

The ethical approval was obtained from the joint University of Ibadan and University College Hospital ethical review board.

\section{Data Collection}

Clinical information was obtained from the subjects and these include demographic information, complaints within the previous six months, frequency of crises, the types of crises experienced and the number of pints of blood transfused annually. Informed consent was taken from both subjects and controls. A blood sample was collected for the estimation of packed cell volume (PCV). Blood pressure (BP) measurements were obtained according to standard guidelines with the aid of a mercury sphygmomanometer (Accoson, London). Subjects and HBA controls were weighed without shoes, headgears or caps and in light clothing on a standard beam balance. Height assessment was made to the 
nearest centimetre, using a stadiometer. Body mass index (BMI) was calculated using the formula BMI = Weight $(\mathrm{kg})$ /Height (M) [2]. Body surface area was calculated using the Dubois formula [9]. Physical examination was done, involving general examination and specific cardiovascular examination. Inspection, palpation and auscultation of the heart was done to characterize heart sounds and note accentuations of the heart sounds, define and grade murmurs and detect added heart sounds. Chest and abdominal examinations were also done to detect signs suggestive of heart failure.

\section{Echocardiographic Evaluation}

A Toshiba Xario 200 XGSSA-600A (Tokyo, Japan) echocardiography machine which is equipped with a $3 \mathrm{MHz}$ (PST-30BT) cardiac transducer was used. Comprehensive echocardiography with simultaneous electrocardiogram including 2-dimensional, M-mode, pulsed-wave doppler (PWD), continuous wave doppler (CWD) and tissue doppler imaging (TDI) was performed on the study participants.

Right ventricular diastolic function was assessed according to the ASE guidelines [10]. These are pulsedwave doppler-derived peak early-diastolic tricuspid inflow (E-wave) velocity, late-diastolic tricuspid inflow (A-wave) velocity, tricuspid E-wave to A-wave velocity ratio (E/A), tricuspid E-wave deceleration time (DT), and isovolumic relaxation time (IVRT) of the RV. Measurements were done in the apical 4 chamber view with the patient in the left lateral decubitus position. The pulsed wave doppler beam was directed parallel to the tricuspid valve, with the sample volume at the tips of the tricuspid valves. Five or more consecutive echo tracings with simultaneous electrocardiogram tracings were visualized. Two major velocities were observed and measured- the first was the peak early (E) and the other, late (A) trans-tricuspid velocities. The E deceleration time was measured from the peak of $E$ to the point of intercept with the baseline.

Pulsed wave tissue doppler imaging (TDI) was acquired according to the recommendations of the ASE [11]. Care was taken to ensure the doppler ultrasound beam was parallel to the tricuspid annular motion. Three major velocities were recorded at the annulus: the peak major positive systolic velocity ( $\mathrm{S}^{\prime}$ ) when the annulus is moving towards the apex and the two peaks of the negative velocities- early (E') and late (A) diastolic velocities when the annulus moves towards the base. The tricuspid E/E' ratio was determined as a surrogate for RV filling pressure.
Grading of RV diastolic dysfunction was done as recommended by the ASE as follows: a tricuspid E/A ratio $<0.8$ suggests impaired relaxation, a tricuspid $\mathrm{E} / \mathrm{A}$ ratio of 0.8 to 2.1 with an $\mathrm{E} / \mathrm{E}$ ratio $>6$ suggest pseudo normal filling and a tricuspid E/A ratio $>2.1$ with deceleration time $<120 \mathrm{~ms}$ suggests restrictive filling [12].

Right atrial area was measured at end systole, corresponding to the end of the electrocardiographic Twave in the apical 4-chamber view [13]. Care was taken to ensure proper visualization of the endocardial border.

Right ventricular area assessment was done using an endocardial tracing of the right ventricle in apical 4 chamber view. Right ventricular areas at end-diastole and end-systole were determined in the apical 4-chamber view. RV Fractional Area Change (FAC) was calculated as:

$$
\text { RVFAC }=\frac{\text { RVenddiastolicarea }- \text { RVendsystolicarea }}{\text { RVenddiastolicarea }}
$$

Care was taken to trace the free wall beneath the trabeculations. Values less than 35\% were considered to be abnormal.

Tricuspid annular plane systolic excursion (TAPSE) was measured in the apical 4- chamber view in M-mode. The beam was directed at the lateral tricuspid annulus with the M-mode cursor placed through the tricuspid annulus. Measurements were made from the peak to the trough of the excursions of the lateral tricuspid annulus during the cardiac cycle. Values less than $1.6 \mathrm{~cm}$ were considered abnormal. Peak velocity of the lateral tricuspid annulus $S^{\prime}$ was measured in the apical 4 chamber view. The pulsed tissue Doppler was directed at the lateral tricuspid annulus, with the sample volume placed directly on the annulus. The major systolic velocity was measured from the peak of the wave to the baseline. Values less than $11.5 \mathrm{~cm} / \mathrm{sec}$ were described as abnormal according to recommendations by the ASE.

The tricuspid regurgitant jet velocity (TRJ) measurements were done in the apical 4-chamber and left parasternal views; preference was given to the view yielding complete envelopes with good-quality. Doppler envelopes with the highest velocities were reported. Care was taken to ensure that the continuous wave doppler beam was parallel to the regurgitant jet. TRJ velocities $\geq$ $2.5 \mathrm{~m} / \mathrm{s}$ were considered elevated.

Right ventricular systolic pressure was estimated for both cases and controls that have tricuspid regurgitation. The modified Bernoulli's equation was used as follows: 
Right ventricular systolic pressure $=4 \mathrm{~V} 2+$ Right atrial pressure

Where the right atrial pressure was estimated from the ratio of the E/E' using this equation which has been standardized and found to correlate with pulmonary catheterization values (from Sade LE, et al.) [14].

$$
\text { Right atrial pressure }=1.62 \times \frac{E}{E^{\prime}}+2.13
$$

Right ventricular systolic pressures $\geq 35 \mathrm{mmHg}$ are considered to be in keeping with pulmonary hypertension. Pulmonary regurgitation was measured in the left parasternal short axis view in continuous wave doppler mode, with the doppler beam directed parallel to the pulmonary valves, also in accordance with standard recommendations.

\section{Data Management and Analysis}

All data obtained were entered into a standard proforma. Continuous variables were expressed as mean \pm standard deviation while categorical variables were expressed as count (percentages). Data analysis was done by IBM SPSS Statistics for Windows, Version 22.0. The Shapiro-Wilks test was used to assess for normality of distribution of variables. Dimensions of the various cardiac chambers were indexed to body surface area as appropriate. The means of continuous variables were compared using the Student's t-test for independent groups. For categorical variables, Chi square and/or Fisher's exact test was applied to test the equality of distributions between the two groups. Analysis of variance was used to compare the various grades of diastolic function between subjects and controls.

The clinical and echocardiographic (ECHO) differences between those with and without PHT were evaluated as appropriate. Binary logistic regression analysis (enter method) was done to determine the independent correlates of right ventricular diastolic dysfunction. This model comprised of the presence of right ventricular dysfunction as the dependent variable while the independent variables were packed cell volume, right atrial area index, body mass index and the sickle cell status. A two tailed p-value less than 0.05 was considered significant.

\section{Results}

\section{Baseline Description of Participants}

Eighty-six (86) SCA patients were recruited from the Haematology clinic of the University College Hospital, Ibadan. Eighty-nine (89) controls with HBA were recruited from the hospital community. (Table 1) shows the socio-demographic characteristics of the subjects and controls. The subjects and controls were comparable in age and sex. Anthropometric dimensions were smaller in SCA subjects than controls. The clinical evaluation also revealed that the subjects had lower systolic blood pressure, diastolic blood pressure and packed cell volume when compared to controls.

\begin{tabular}{|c|c|c|c|}
\hline \multirow{2}{*}{ Variables } & SCA Subjects & Controls & \multirow{2}{*}{ P-value } \\
\cline { 2 - 3 } & $\mathbf{n = 8 6 ( 1 0 0 \% )}$ & $\mathbf{n = 8 9 ( 1 0 0 \% )}$ & \\
\hline Sex (n, \%) & & & 0.46 \\
\hline Male & $43(48.1)$ & $40(45.6)$ & 0.275 \\
\hline Female & $43(51.9)$ & $49(54.4)$ & 0 \\
\hline Age (mean, SD) & $27.6 \pm 7.6$ & $28.9 \pm 8.9$ & 0 \\
\hline Hip circumference (cm) & $86.6 \pm 7.7$ & $97.6 \pm 10.0$ & 0 \\
\hline Waist Circumference (cm) & $74.8 \pm 8.1$ & $81.9 \pm 10$ & 0 \\
\hline Body mass index(Kg.m $\left.{ }^{2}\right)$ & $19.5 \pm 2.8$ & $24.3 \pm 4.2$ & 0 \\
\hline Body surface area(m $\left.{ }^{2}\right)$ & $1.6 \pm 0.3$ & $1.8 \pm 0.3$ & 0.087 \\
\hline Pulse Rate (beats/min) & $80 \pm 12.9$ & $70.6 \pm 10$ & 0.033 \\
\hline Respiratory rate(sec $\left.{ }^{-1}\right)$ & $20.1 \pm 3.9$ & $19.1 \pm 3.7$ & 0 \\
\hline Systolic blood pressure (mmHg) & $111.4 \pm 11.1$ & $114.4 \pm 9.3$ & 0 \\
\hline Diastolic blood pressure (mmHg) & $62.8 \pm 14.6$ & $73.5 \pm 8.3$ & $43.2 \pm 5.5$ \\
\hline Packed cell volume (\%) & $25.6 \pm 5.4$ & & \\
\hline
\end{tabular}

Table 1: Socio-demographic and anthropometric characteristics of participants. 
Table 2 shows the right ventricle, the right atrium and the aortic root. Dimensions are also indexed to body surface area. All dimensions are significantly larger in subjects than controls.

\begin{tabular}{|c|c|c|c|}
\hline ECHO Variables & Subjects $(n=84)$ & Controls $(n=89)$ & P value \\
\hline RV internal diameter in diastole index $\left(\mathrm{cm} \cdot \mathrm{m}^{-2}\right)$ & $2.0 \pm 0.4$ & $1.79 \pm 0.2$ & 0 \\
\hline RV subcostal wall thickness index $\left(\mathrm{cm} \cdot \mathrm{m}^{-2}\right)$ & $0.25 \pm 0.1$ & $0.17 \pm 0.1$ & 0 \\
\hline RV outflow tract index (PSAX view) $\left(\mathrm{cm}^{-\mathrm{m}^{-2}}\right)$ & $1.52 \pm 0.3$ & $1.2 \pm 0.2$ & 0 \\
\hline Right atrial diameter index(major) $\left(\mathrm{cm} \cdot \mathrm{m}^{-2}\right)$ & $3.2 \pm 0.5$ & $2.5 \pm 0.4$ & 0 \\
\hline Right atrial diameter index(minor) $\left(\mathrm{cm}^{-\mathrm{m}^{-2}}\right)$ & $2.65 \pm 0.5$ & $2.12 \pm 0.5$ & 0 \\
\hline Right atrial area index $\left(\mathrm{cm}^{2} \cdot \mathrm{m}^{-2}\right)$ & $10.6 \pm 3.5$ & $8.2 \pm 1.6$ & 0 \\
\hline Right ventricular end diastolic area index $\left(\mathrm{cm}^{2} \cdot \mathrm{m}^{-2}\right)$ & $15.7 \pm 3.4$ & $11.83 \pm 2.4$ & 0 \\
\hline Right ventricular end systolic area index $\left(\mathrm{cm}^{2} \cdot \mathrm{m}^{-2}\right)$ & $9.4 \pm 2.5$ & $7.3 \pm 1.9$ & 0 \\
\hline Aortic valve opening index $\left(\mathrm{cm} \cdot \mathrm{m}^{-2}\right)$ & $1.29 \pm 0.2$ & $1.1 \pm 0.1$ & 0 \\
\hline Aortic diameter index $\left(\mathrm{cm} \cdot \mathrm{m}^{-2}\right)$ & $1.64 \pm 0.3$ & $1.4 \pm 0.2$ & 0 \\
\hline
\end{tabular}

Table 2: Dimension of the right ventricle, right atrium and aortic root of both subjects and controls Key: PLAX: Parasternal long axis view. PSAX: Parasternal short axis view; RV: Right ventricular

Table 3 shows the echocardiographic systolic and diastolic parameters of the participants. There was significant difference in the values of E-wave, A-wave, deceleration time (DCT), TAPSE and peak tricuspid annular systolic velocity $\left(\mathrm{S}^{\prime}\right)$ between the cases and controls, with the subjects (i.e. people with SCA) having higher mean values. There was no significant difference between the subjects and controls. None of the cases or controls had restrictive status.

\begin{tabular}{|c|c|c|c|}
\hline Echocardiography Variables & Subjects(n=86) & Controls(n=89) & P-value \\
\hline Right atrial area index $\left(\mathrm{cm}^{2} \cdot \mathrm{m}^{-2}\right)$ & $10.6 \pm 3.5$ & $8.2 \pm 1.6$ & 0 \\
\hline Trans-tricuspid E-wave velocity $\left(\mathrm{cm} . \mathrm{s}^{-1}\right)$ & $60.7 \pm 14.5$ & $49.8 \pm 12.3$ & 0 \\
\hline Trans-tricuspid A-wave velocity $\left(\mathrm{cm} \cdot \mathrm{s}^{-1}\right)$ & $40 \pm 12.4$ & $32.9 \pm 9.1$ & 0 \\
\hline Isovolumic relaxation time (msec) & $83.8 \pm 38.1$ & $87.1 \pm 28$ & 0.515 \\
\hline Trans-tricuspid E-Deceleration time (msec) & $217.8 \pm 51.6$ & $190.6 \pm 47.3$ & 0 \\
\hline Right $\mathrm{E} / \mathrm{E}^{\prime}$ ratio & $4.46 \pm 2.2$ & $3.83 \pm 1.2$ & 0.019 \\
\hline Right E/A ratio & $1.59 \pm 0.4$ & $1.60 \pm 0.5$ & 0.968 \\
\hline Tricuspid annular plane systolic excursion(cm) & $29.5 \pm 4.6$ & $23.1 \pm 3.6$ & 0 \\
\hline Peak systolic velocity of the lateral tricuspid annulus $(\mathrm{cm} / \mathrm{s})$ & $15.9 \pm 3.1$ & $14.4 \pm 2.9$ & 0 \\
\hline Right ventricular fraction area change & $0.4 \pm 0.1$ & $0.38 \pm 0.2$ & 0.34 \\
\hline Right ventricular Index of myocardial performance & $0.59 \pm 0.2$ & $0.61 \pm 0.2$ & 0.395 \\
\hline Tricuspid regurgitant velocity $\left(\mathrm{cm}^{\mathrm{sec}} \mathrm{se}^{-1}\right)$ & $204.8 \pm 54.1$ & $179.4 \pm 49.7$ & 0.05 \\
\hline Right ventricular systolic pressure $(\mathrm{mmHg})$ & $27.6 \pm 13.3$ & $23.3 \pm 5.7$ & 0.105 \\
\hline Diastolic function: Normal & $74(86)$ & $83(93.2)$ & \\
\hline Grade 1 diastolic dysfunction & $2(2.3)$ & $3(3.4)$ & 0.109 \\
\hline Grade 2 diastolic dysfunction & $10(11.6)$ & $3(3.4)$ & \\
\hline
\end{tabular}

Table 3: Systolic and diastolic echocardiographic parameters of participants, including tricuspid regurgitant velocity Key: E/A Ratio of early to late trans-tricuspid velocity; E/E': Ratio of early trans-tricuspid velocity to the early tricuspid annular diastolic velocity.

Table 4 highlights the cardiac structural and functional differences between those with normal diastolic function and those with diastolic dysfunction. With exception of left ventricular internal diameter in systole, the left and right ventricular chambers are larger in those with diastolic dysfunction. The body mass index is smaller in those with diastolic dysfunction. The $E / E^{\prime}$ is higher in those with diastolic dysfunction. 


\begin{tabular}{|c|c|c|c|}
\hline Variables & Normal & $\begin{array}{c}\text { Diastolic } \\
\end{array}$ & P value \\
\hline Variaidies & Diastolic Function ( $n=72)$ & Dysfunction $(n=12)$ & P value \\
\hline Tricuspid annular systolic plane excursion(cm) & $29.4 \pm 4.6$ & $29 \pm 4.8$ & 0.781 \\
\hline Peak systolic velocity of the tricuspid annulus $\mathrm{S}^{\prime}\left(\mathrm{cm} \cdot \mathrm{s}^{-1}\right)$ & $16 \pm 3.2$ & $14.9 \pm 1.8$ & 0.241 \\
\hline Right ventricular fractional area change & $0.40 \pm 0.1$ & $0.38 \pm 0.1$ & 0.507 \\
\hline Myocardial performance index & $0.59 \pm 0.2$ & $0.59 \pm 0.1$ & 0.18 \\
\hline $\mathrm{E} / \mathrm{A}$ & $1.6 \pm 0.4$ & $1.49 \pm 0.4$ & 0.422 \\
\hline $\mathrm{E} / \mathrm{E}^{\prime}$ & $4.1 \pm 1.3$ & $7.97 \pm 3.1$ & 0.001 \\
\hline E Deceleration time (msec) & $218 \pm 54.5$ & $217.6 \pm 33.2$ & 0.979 \\
\hline RA Area index $\left(\mathrm{cm}^{2} \cdot \mathrm{m}^{-2}\right)$ & $11.1 \pm 2.6$ & $13.0 \pm 4.9$ & 0.045 \\
\hline Isovolumic relaxation time (msec) & $84.4 \pm 37.3$ & $71.9 \pm 32$ & 0.293 \\
\hline Packed cell volume (\%) & $26.3 \pm 5$ & $21.7 \pm 6$ & 0.07 \\
\hline RV end diastolic area index $\left(\mathrm{cm}^{2} \cdot \mathrm{m}^{-2}\right)$ & $15.1 \pm 3.1$ & $18.3 \pm 3.8$ & 0.002 \\
\hline RV end systolic area index $\left(\mathrm{cm}^{2} \cdot \mathrm{m}^{-2}\right)$ & $8.9 \pm 2.2$ & $11.3 \pm 2.9$ & 0.002 \\
\hline LV internal diameter in diastole index $\left(\mathrm{cm} \cdot \mathrm{m}^{-2}\right)$ & $3.2 \pm 0.5$ & $3.6 \pm 0.8$ & 0.026 \\
\hline LV internal diameter in systole index $\left(\mathrm{cm} \cdot \mathrm{m}^{-2}\right)$ & $2.1 \pm 0.3$ & $2.3 \pm 0.5$ & 0.145 \\
\hline LV ejection fraction & $0.53 \pm 0.4$ & $0.61 \pm 0.1$ & 0.543 \\
\hline Tricuspid regurgitation velocity $(\mathrm{cm} / \mathrm{sec})$ & $201.4 \pm 47.3$ & $317.5 \pm 13.4$ & 0.002 \\
\hline Body mass index(kg.m-2 $\left.{ }^{2}\right)$ & $19.8 \pm 2.8$ & $17.3 \pm 2.3$ & 0.006 \\
\hline
\end{tabular}

Table 4: Clinical and Echo features of sickle cell anaemia subjects with and without diastolic dysfunction.

Key: E/A-Early to late trans-tricuspid velocity ratio; E/E'-Early trans-tricuspid velocity to the early tricuspid annular diastolic velocity ratio. LV-Left ventricular; RV-Right ventricular

Binary logistic regression was done do evaluate the determinants of right ventricular diastolic dysfunction. Table 5 shows the model. The body mass index (BMI) and right atrial area were found to be significant predictors of diastolic dysfunction, with low BMI increasing the risk of developing diastolic dysfunction.

\begin{tabular}{|c|c|c|c|}
\hline Variables & Odds ratio & P value & Confidence Interval \\
\hline Packed cell volume & 0.932 & 0.191 & $0.838-1.036$ \\
\hline Body mass index & 0.802 & 0.029 & $0.658-0.980$ \\
\hline Right atrial area index $\left(\mathrm{cm}^{2} \cdot \mathrm{m}^{-2}\right)$ & 1.14 & 0.214 & $0.927-1.403$ \\
\hline Sickle cell status & 0.137 & 0.093 & $0.013-1.397$ \\
\hline
\end{tabular}

Table 5: Binary logistic regression to predict the determinants of diastolic dysfunction in subjects with sickle cell anaemia and controls

\section{Discussion}

\section{Right Ventricular Systolic Function of Subjects and Controls}

Right ventricular systolic function was essentially normal in both sicklers and controls. TAPSE and $\mathrm{S}^{\prime}$, which are markers of longitudinal shortening, were notably higher among subjects than controls. This finding is similar to those from Blanc et al [15]. The increased longitudinal shortening of the RV, coupled with the increase in heart rate and stroke volume, suggests that the heart of the sickle cell anaemia subjects does more work at rest than that of the HBA controls. This appears to be a compensatory mechanism for the reduced oxygen carrying capacity of the blood of people with SCA. However, the study of Knight-Perry et al. showed that the $S^{\prime}$ was paradoxically reduced in the sickle cell group as compared to the controls [8]. This could possibly be due to the composition of those studied, as only $68 \%$ of those in their sickle cell group had SCA. Most of the others had S- Thalassemia and Haemoglobin SC- both of which could be responsible for the incongruence of findings.

Right ventricular fractional area change (RV FAC) was similar among subjects and controls. This is similar to findings in other studies $[3,16]$. These suggest that right ventricular systolic function is essentially preserved in sickle cell patients. Longitudinal shortening of the right ventricle, of which TAPSE and $S^{\prime}$ are indices, is actually 
significantly increased in sickle cell cases, which is a physiologic response to the increased preload seen in anaemic patients. In $\beta$ Thalassemia major patients however, a significant difference in TAPSE and S' were not found when compared with non- anaemic controls by Barbero et al., possibly due to a much smaller sample size and cardiac iron overload [17].

\section{Right Ventricular Diastolic Function of Subjects and Controls}

Early trans-tricuspid diastolic velocity (E), late transtricuspid diastolic velocity (A), E deceleration time (E Dct), E/A, IVRT and right atrial area were the measures of diastolic function in this study. Of these, the subjects with sickle cell had higher E, A, E-Deceleration time and right atrial area values than controls - all of which were statistically significant. However, these are not used in isolation while evaluating diastolic function. The E/A ratio however, which has been extensively validated, was comparable between subjects and controls. This is similar to findings from Sachdev and colleagues [16] The RV E/E' ratio, which is an indirect method of assessing right atrial pressure [18] in addition to assessing diastolic function, was higher in the SCA group as compared to controls. Knight-Perry and colleagues also found increased RV E/E' in the SCA group as compared with controls in their study [8]. In SCA, the E and A velocities are both increased as compared to controls. However, because impaired relaxation of the $\mathrm{RV}$ is estimated using the $\mathrm{E} / \mathrm{A}$ ratio, the resultant is that of normal relaxation in most of the subjects. This study suggests that the RV dilates in SCA with largely preserved relaxation characteristics.

Right atrial area, which has been recommended as a measure of diastolic function assessment by the ASE, was found to be larger among the subjects as compared with controls. The impact of the gender on cardiac chamber size has been well described, with the male sex having relatively larger cardiac chamber dimensions than females. When right atrial size was compared between those without diastolic dysfunction and those with diastolic dysfunction, the latter has larger right atrial sizes as should be expected.

Body mass index (BMI) was found to be a significant predictor of diastolic dysfunction in this study, with low BMI conferring increased risk of developing diastolic dysfunction on the sickle cell populace. This suggests that people with SCA who are underweight (cachectic) may be predisposed to developing diastolic dysfunction. This is in keeping with findings from Melenovsky et al., which showed that cachexia and right ventricular dysfunction are related in a bidirectional way [19]. Elevated right atrial pressures, of which increased $E / E^{\prime}$ is a surrogate marker, was found in patients with low BMI by Carr JG, et al. and was found to be the only significant haemodynamic predictor of malnutrition in their study [20]. This has been corroborated in some studies that showed a link between cachexia and right ventricular dysfunction [21,22], whether the weight loss is cardiac in origin or not [19].

Impaired RV function can impact negatively on lean and fat body mass in diverse ways. These include anorexia, splanchnic congestion and reduced intestinal blood flow [23], impaired intestinal motility, fat malabsorption [24], increased intestinal permeability and endotoxin translocation [25]. However, cachexia has also been shown to impact negatively on RV function, with elaboration of cytokines like tumour necrosis factor- $\alpha$, interleukins 2 and 6, which have a negatively inotropic effect on the heart [26]. These findings suggest that reversal of the cachectic state may improve right ventricular function. The aetiology of cachexia in SCA appears to be multifactorial, and could be a manifestation of growth retardation, which has been well documented in people with SCA. It has been linked to nutritional [27]. Genetic [28] and endocrine related problems [29]. Nutrition however seem to be the most important factor, as improvements were noticed in those aggressively fed [30].The impact of tachycardia on diastolic function has been well described [31,32], with reduction in time-based parameters like IVRT and accentuation of both $\mathrm{E}$ and $\mathrm{A}$ velocities. These were noted in this study.

\section{Limitations}

Using echocardiography to evaluate cardiac function is good but limited. The impact of coronary artery patency and function, dysrhythmias, subclinical myocarditis and possible concurrent endocrinopathies and metabolic problems was not evaluated. These could be responsible for certain differences that were observed in both the cases and controls. Two-dimensional echocardiography, though good for assessing both the structure and function of the heart, is not the gold standard. Other imaging modalities like cardiac MRI and 3D echocardiography have surpassed 2D echocardiography in characterizing the peculiar crescentic shape of the right ventricle and are more accurate in measuring RV volumes and global ventricular function [33,34]. Two-dimensional echocardiography has been shown to underestimate RV volumes, and more so in dilated ventricles [35]. 


\section{Conclusion}

The sickle cell populace have dilated cardiac chambers, increased stroke volume and normal systolic function as compared with controls. Some however have diastolic dysfunction as evidenced by right ventricular E/A ratio and $E / E^{\prime}$ ratio. Low BMI was found to be a predictor of right ventricular diastolic dysfunction in this study. These could be adaptive mechanisms to the chronic anaemia and haemolysis that is found in this haemoglobinopathy.

\section{References}

1. Akgul F, Yalcin F, Babayigit C, Seyfeli E, Seydaliyeva T, et al. (2006) Right ventricular and pulmonary function in sickle cell disease patients with pulmonary hypertension. Pediatr Cardiol 27(4): 440446.

2. Gacon PH, Donatien Y (2001) Cardiac manifestations of sickle cell anemia. Presse Med 30(17): 841-845.

3. Qureshi N, Joyce JJ, Qi N, Chang RK (2006) Right ventricular abnormalities in sickle cell anemia: Evidence of a progressive increase in pulmonary vascular resistance. J Pediatr 149(1): 23-27.

4. Vonk-Noordegraaf A, Haddad F, Chin KM, Forfia PR, Kawut SM, et al. (2013) Right Heart Adaptation to Pulmonary Arterial Hypertension. J Am Coll Cardiol 62(25): 22-33.

5. Abdul-Mohsen MF (2012) Echocardiographic evaluation of left ventricular diastolic and systolic function in Saudi patients with sickle cell disease. J Saudi Hear Assoc 24(4): 217-224.

6. Castro 0, Hoque M, Brown BD (2003) Pulmonary hypertension in sickle cell disease: cardiac catheterization results and survival. Blood 101(4): 1257-1261.

7. Ballas SK (2012) More definitions in sickle cell disease: Steady state v base line data. Am J Hematol 87(3): 338-338.

8. Knight-Perry JE, de las Fuentes L, Waggoner AD, Hoffmann RG, Blinder MA, et al. (2011) Abnormalities in Cardiac Structure and Function in Adults with Sickle Cell Disease are not Associated with Pulmonary Hypertension. J Am Soc Echocardiogr 24(11): 12851290.
9. Du Bois D, Du Bois EF (1989) A formula to estimate the approximate surface area if height and weight be known 1916. Nutrition 5(5): 303-311.

10. Nageh MF, Kopelen HA, Zoghbi WA, Quiñones MA, Nagueh SF (1999) Estimation of mean right atrial pressure using tissue Doppler imaging. Am J Cardiol 84(12): 1448-1451.

11. Rudski LG, Lai WW, Afilalo J, Hua L, Handschumacher MD, et al. (2010) Guidelines for the echocardiographic assessment of the right heart in adults: a report from the American Society of Echocardiography endorsed by the European Association of Echocardiography, a registered branch of the European Society of Cardiology, and the Canadian Society of Echocardiography. J Am Soc Echocardiogr 23(7): 685-713.

12. Alam M, Wardell J, Andersson E, Samad BA, Nordlander R (1999) Characteristics of Mitral and Tricuspid Annular Velocities Determined by Pulsed Wave Doppler Tissue Imaging in Healthy Subjects. J Am Soc Echocardiogr 12(8): 618-628.

13. Lang R, Bierig M, Devereux R, Flachskampf F, Foster $E$, et al. (2006) Recommendations for chamber quantification. Eur J Echocardiogr 7(2): 79-108.

14. Sade LE, Gulmez O, Eroglu S, Sezgin A, Muderrisoglu H (2007) Noninvasive estimation of right ventricular filling pressure by ratio of early tricuspid inflow to annular diastolic velocity in patients with and without recent cardiac surgery. J Am Soc Echocardiogr 20(8): 982-988.

15. Blanc J, Stos B, de Montalembert $M$, Bonnet $D$, Boudjemline Y (2012) Right ventricular systolic strain is altered in children with sickle cell disease. J Am Soc Echocardiogr 25(5): 511-517.

16. Sachdev V, Machado RF, Shizukuda Y, Rao YN, Sidenko S, et al. (2007) Diastolic Dysfunction Is an Independent Risk Factor for Death in Patients With Sickle Cell Disease. J Am Coll Cardiol (4): 472-9.

17. Barbero U, Destefanis P, Pozzi R, Longo F, Piga A (2012) Exercise Stress Echocardiography with Tissue Doppler Imaging (TDI) Detects Early Systolic Dysfunction in Beta-Thalassemia Major Patients without Cardiac Iron Overload. Mediterr J Hematol Infect Dis 4(1): 2012037. 
18. Said K, Shehata A, Ashour Z, El-Tobgi S (2012) Value of Conventional and Tissue Doppler Echocardiography in the Noninvasive Measurement of Right Atrial Pressure. Echocardiography 29(7): 779-784.

19. Melenovsky V, Kotrc M, Borlaug BA, Marek T, Kovar J, et al. (2013) Relationships Between Right Ventricular Function, Body Composition, and Prognosis in Advanced Heart Failure. J Am Coll Cardiol 62(18): 1660-1670.

20. Carr JG, Stevenson LW, Walden JA, Heber D (1989) Prevalence and hemodynamic correlates of malnutrition in severe congestive heart failure secondary to ischemic or idiopathic dilated cardiomyopathy. Am J Cardiol 63(11): 709-713.

21. Ajayi AA, Adigun AQ, Ojofeitimi EO, Yusuph H, Ajayi OE (1999) Anthropometric evaluation of cachexia in chronic congestive heart failure: the role of tricuspid regurgitation. Int J Cardiol 71(1): 79-84.

22. Horwich TB, Fonarow GC, Hamilton MA, MacLellan WR, Woo MA, et al. (2001) The relationship between obesity and mortality in patients with heart failure. J Am Coll Cardiol 38(3): 789-795.

23. Sandek A, Swidsinski A, Schroedl W, Watson A, Valentova M, et al. (2014) Intestinal Blood Flow in Patients With Chronic Heart Failure A Link With Bacterial Growth, Gastrointestinal Symptoms, and Cachexia. J Am Coll Cardiol 64(11): 1092-1102.

24. King D, Smith Ml, Chapman Tj, Stockdale Hr, Lye M Fat (1996) Malabsorption in Elderly Patients with Cardiac Cachexia. Age Ageing 25(2): 144-149.

25. Niebauer J, Volk H-D, Kemp M, Dominguez M, Schumann RR, et al. (1999) Endotoxin and immune activation in chronic heart failure: a prospective cohort study. The Lancet 353(9167): 1838-1842.

26. Levine B, Kalman J, Mayer L, Fillit HM, Packer M (1990) Elevated Circulating Levels of Tumor Necrosis Factor in Severe Chronic Heart Failure. N Engl J Med 323(4): 236-241.
27. Hyacinth HI, Adekeye OA, Yilgwan CS (2013) Malnutrition in Sickle Cell Anemia: Implications for Infection, Growth, and Maturation. J Soc Behav Heal Sci 7(1).

28. Modebe O, Ifenu SA (1993) Growth retardation in homozygous sickle cell disease: Role of calorie intake and possible gender-related differences. Am J Hematol 44(3): 149-154.

29. Odonkor PO (1983) Metabolic and endocrine basis of the growth retardation in sickle cell disease. Bull Eur Physiopathol Respir 19(4): 357-359.

30. Heyman M, Katz R, Hurst D, Chiu D, Ammann A, Vichinsky E, et al. (1985) Growth Retardation in Sickle-Cell Disease Treated by Nutritional Support. The Lancet 325(8434): 903-906.

31. Yu C-M, Lin H, Ho P-C, Yang H (2003) Assessment of Left and Right Ventricular Systolic and Diastolic Synchronicity in Normal Subjects by Tissue Doppler Echocardiography and the Effects of Age and Heart Rate. Echocardiography 20(1): 19-27.

32. Selby DE, Palmer BM, LeWinter MM, Meyer M (2011) Tachycardia-Induced Diastolic Dysfunction and Resting Tone in Myocardium from Patients with a Normal Ejection Fraction. J Am Coll Cardiol 58(2): 147-154.

33. Meloni A, Detterich J, Berdoukas V, Pepe A, Lombardi $M$, et al. (2013) Comparison of biventricular dimensions and function between pediatric sickle-cell disease and thalassemia major patients without cardiac iron. Am J Hematol 88(3): 213-218.

34. Nguyen K-L, Tian X, Alam S, Mehari A, Leung SW, Seamon C, et al. (2016) Elevated transpulmonary gradient and cardiac magnetic resonance-derived right ventricular remodeling predict poor outcomes in sickle cell disease. Haematologica 101(2): 40-43.

35. Lai WW, Gauvreau K, Rivera ES, Saleeb S, Powell AJ, et al. (2008) Accuracy of guideline recommendations for two-dimensional quantification of the right ventricle by echocardiography. Int J Cardiovasc Imaging 24(7): 691-698. 